\title{
Alone or Together in the Neighbourhood? School Choice and pÿFamilies Access to Local Social Networks
}

Kosunen, Sonja

2018

Kosunen , S \& Rivière , C 2018 , ' Alone or Together in the Neighbourhood? School Choice pÿand Families Access to Local Social Networks ' , Children's Geographies , vol. 16 , no. 2 , pp. 143-155 . https://doi.org/10.1080/14733285.2017.1334114

http://hdl.handle.net/10138/309603

https://doi.org/10.1080/14733285.2017.1334114

acceptedVersion

Downloaded from Helda, University of Helsinki institutional repository.

This is an electronic reprint of the original article.

This reprint may differ from the original in pagination and typographic detail.

Please cite the original version. 


\title{
Alone or Together in the Neighbourhood? School Choice and Families' Access to Local Social Networks
}

\section{Authors:}

\section{Sonja Kosunen}

Research Unit focusing on Sociology and Politics of Education, Faculty of Educational Sciences, University of Helsinki, Finland

2. Clément Rivière

CeRIES, Université Charles de Gaulle - Lille 3, France

\section{Corresponding author:}

Sonja Kosunen, Research Unit focusing on Sociology and Politics of Education, Faculty of Educational Sciences, Siltavuorenpenger 5, P.O. Box 9, 00014 University of Helsinki, Finland Email: sonja.kosunen@helsinki.fi

\begin{abstract}
This study explores how the everyday geographies of city life and families' access to social networks in the neighbourhood influence families' school choices. The data consists of thematic interviews with parents of 8-14-year-old children $(n=170)$ in three urban areas located in the cities of Paris (France), Milan (Italy) and Espoo (Finland) and are analysed via qualitative content analysis. The findings indicate that the families' access to local social networks influence the reasoning behind school choice to the local school. The children's relationships with other children and adults in the neighbourhood are considered important, but additionally the parents' networks with other parents in the area, mediated by the school, play their role. School choices as practices should therefore be analysed not merely as choices of an institution, as they comprise of various aspects concerning the surrounding neighbourhood as a physical and social space.
\end{abstract}

Keywords: school choice, parents, children, urban space, social capital, social networks

\section{Introduction}

This paper focuses on the school-mediated social networks of families and the influence of these relationships when discussing the school choices of their children in cities. The school 
choices of families are characteristically an urban phenomenon and have lately been widely studied across cities, especially in Europe (e.g. Butler and Robson 2003; Gustafson 2011; Oberti 2007; Reay 2004; Seppänen et al. 2015; van Zanten 2009) and North America (e.g. Berends 2014). In spite of a current fruitful dialogue between the realms of school choice, urban research and geographies of education (e.g. Ball and Vincent 2007; Oberti 2007; PoseyMaddox Kimelberg, and Cucchiara 2016; van Zanten 2009), explanations for choosing or not choosing a certain school have often focused mainly on the actual school as an institution and as an environment affecting the choice process (i.e. the quality of teaching, peer-group composition and the school's reputation). However, the influential roles of social networks and grapevine information that is spread in the social networks of families regarding the schools have been acknowledged across contexts (e.g. Ball and Vincent 1998; Kosunen 2014). What could be investigated more are the school-mediated social networks, actual friendships and relationships providing mutual help among children and adults in cities that are in different ways influencing the views of schooling (see also Vincent, Neal, and Iqbal 2016) and the process of choosing a school.

School choices and urban segregation are often in the core of studies focusing on educational inequalities and their reproduction from different angles. Holloway et al. (2010), in their critical exploration of the cross-disciplinary nature around the geographies of education, point out the importance of focusing on the analysis of education 'as vital sphere of social reproduction and inequality'. They analyse how education is shaped by socially specific understandings of childhood and aim to create more understanding of children's experiences of education (Holloway et al. 2010, 3; see also Karsten 2015). Educational provision tends to be differentiated within urban space, and that is why schooling plays a role in families' residential choices and consequently is related to urban segregation (e.g. Butler and Robson 2003; Butler and van Zanten 2007). This influences the 'physical and affective micro-spaces in which the children interact' (Vincent, Neal, and Iqbal 2016, 482) in their daily lives. The spaces of interaction do not need to touch only upon the school environment but additionally the personal relationships mediated by the school. This again has its impact on the ways in which families discuss the choice of a school for their child. 
The rather old basic assumption of Ball, Bowe, and Gewirtz (1995) is to consider parental choice of a school a combination of space, social class and the actual choice. van Zanten (2009) adds to this discussion that school choice should not be treated as any choice, but as a particularly important one, due to its long-term consequences in the life-course of the child, and also due to its affective component, as it is connected to formulating social relationships with others. Therefore, this study focuses on the school choice as an outcome, as it is a process that mediates and is mediated by different social relationships. This is the standpoint we take in this study, elaborating especially on the relation between the residential space and the school choice: we study how the choices of families can be influenced by the surrounding neighbourhood and by the social networks that come along with the choice of a local school. The urban space is both embedded in the choice (e.g. providing limitations of which schools are actually physically reachable for the family), and formulates it in social terms (e.g. when evaluating at the socio-demographic features of a neighbourhood and presuming something about the social composition, promoted habitus and levels of school well-being).

This study aims to contribute to deepen the analysis in this respect by focusing on the impact of the everyday geographies on school choice, which are related to the children's and parents' activities and social relations in the neighbourhood and in the city and influence the choice of a school in three different contexts: cities in Finland (Espoo), France (Paris) and Italy (Milan). The research task was to analyse which social features around local public schools (defined as the nearest to home, fiscally funded school) are taken into account and reasoned in the interviews conducted with parents $(n=170)$ when choosing a school for children in the comprehensive school stage. We aim to enhance understanding of how families' access to local social capital, defined in a Bourdieusian perspective (Bourdieu 1980), as the resources deriving from access to social networks at the local level can shape their school choices. As practical examples illustrating the forms of social networks embedded in urban educational choices, we use the parental concerns related to the journey to school and shared parental supervision of children in cities. What is known from previous studies in the field is that children's use of urban public space and parental concerns have significantly evolved over the last decades in Western countries (Bunar and Ambrose 2016; Karsten 2005; see also Valentine and McKendrick 1997). The point here is to investigate the ways in which the social relations in the surrounding neighbourhood of the school influence the reasoning behind the choice. 


\section{School choice, urban space and families' local socialisation}

School choice is a two-folded phenomenon, which comprises families choosing schools and schools selecting (some of) their pupils. Especially as the children grow older, the decision of families' choosing a school is an interactive process, where the children participate in the decision-making with their parents on which school to choose and why (van Zanten 2009). This is due to the fact that, quite often, the process where the middle-class children are presumably choosing a school themselves, the starting point and the choice set (Bell 2009) already include a pre-selection of institutions by the parents (van Zanten 2009). This means that the parents provide the child a set of schools from which to choose, either due to accessibility, proximity or other reasons, and then 'the child makes the decision'. Due to this, this study treats school choice as a family matter, not solely as child's decision.

The large part of the debate has concentrated on the choice between public and private schools with diverse symbolic hierarchies, middle-class practices of avoiding disreputable local schools, and on the neighbourhood characteristics impacting the choosing behaviour of families (e.g. Butler and Robson 2003). Taylor (2001) points out that meritorious research on parental school choice sometimes implies that the local school has not been as strong a candidate for families as some other types of school with more prestigious reputations, but are located possibly further away. However, there seems to be some kind of a shift in the trend of strongly acknowledging the role of the urban surrounding of the school both socially, physically as well as emotionally as a part of the school choice process. As stated by PoseyMaddox, Kimelberg, and Cucchiara (2016), nowadays, the academic discussion about school choice no longer remains simply on families 'shopping' for the 'best' school available in the education market, nor only on the experienced relative deficit of the lower class families due to middle-class school choice to further schools. There is an increasing body of literature dealing with urban middle-class families choosing the local public (fiscally funded) school for ideological, political and practical reasons (e.g. Raveaud and van Zanten 2007). Those parents often expect positive outcomes for the children from exposure to diversity at school (PoseyMaddox, Kimelberg, and Cucchiara 2016). 
Active middle-class participation in the local public schools through residential and school choices push for better maintenance and services of the schools, and advocate for changes in the pedagogies, policies and resourcing. These practices make the local, socially mixed schools attractive for also other middle-class families by many means (Posey-Maddox, Kimelberg, and Cucchiara 2016). The underlying idea tends often to be ideological: supporting local provision is discursively equivalent to not openly promoting social distinction. This idea seems to be prominent, especially among the intellectual fractions of the middle classes (van Zanten 2009). However, these analyses of middleclass school choices towards the local school still concentrate on the role of the school as a pedagogical and social environment. Less is stated about the urban surroundings around the school.

One of the core questions in urban educational choice is the families' willingness to become socialised in the more or less socially mixed neighbourhood, which in research then often reverts to the question of whether or not to choose the local school, which often works as a mediator in this process (see Weller and Bruegel 2009). There are at least three distinct ways in which parents may approach such a choice: first, as mentioned above, as a choice of institution according to personal preferences in relation to its perceived features (including their specific preferences and who the choosers are in terms of gender, ethnicity and social class), second, as an ideological question, and/or third, as a practical question concerning the length and safety of the journey to the local school.

The ideological part of choosing the local school is an interesting one, as it includes aspects of families as citizens, not only choosers in the educational market. The distinction between the local school and schooling at a longer distance is still not as straightforward as one might expect. The hegemonic discourse still is that 'responsible citizens' with a middle-class background, especially those living in socio-economically mixed neighbourhoods, would choose a local school for their children (Posey-Maddox, Kimelberg, and Cucchiara 2016). 'Good parents', on the other hand, should choose the 'best match' of schools from all the available options, and this match might not favour a local school (Oría et al. 2007). However, the best match in the eyes of a middle-class family living in a middle-class neighbourhood might be the local school. Then, the choice 'supports' the local school and neighbourhood, but not the underlying idea behind the ideological discussion of social mixing and integration in 
schools as a value per se. The parental choice of a local school does not predict any form of support for the idea of social mixing in the local area and its schools, if the area has a particular social profile to start with. Therefore, the discussion in which the local school as a concept replaces the phenomenon of choosing school with a socio-economically mixed composition of pupils (and possibly 'tough' surrounding neighbourhoods) covers up some of the inequalities that only become visible, when the choice of a local school is unravelled into a discussion of social relationships and investigated from more of an urban perspective.

An influential third factor affecting the school-choice process is the question of everyday practices: how to get to (and come back home from) school and who looks after the children before and after school. The journey to school is generally the earliest form of autonomous or semi-autonomous mobility in the usual life-course of children in European countries (Vercesi 2008). Simultaneously children's mobility in the urban public space is a general concern for parents (Pain 2006), as they are often perceived as not competent enough to venture alone in public spaces (Cahill 1990). Children's presence in urban public spaces has declined in recent decades in Western countries and they are more likely to be taken to and from school by car than some decades ago (see e.g. McMillan 2005). There are journey-related outer risks such as involvement in traffic accidents and a stranger-danger (Pain 2006), meaning a threat of a dangerous intervention of a stranger when children move alone, especially in cities that from a sociological standpoint can be defined as a 'world of strangers' (Lofland 1973). Traffic and stranger-danger can be concerns in rural spaces as well (e.g. Valentine 1997a), but these aspects become sharpened in urban spaces. Children's autonomous mobility becomes a matter in school choice and local social relationships, when families evaluate their child's capacities of facing these requirements alone or in a group of children.

Children play a mediating role in developing their parents' social networks in the neighbourhood (Weller and Bruegel 2009). Schools serve as central meeting and socialising places in different kinds of urban and local contexts (Karsten, Lupi, and Stiger-Speksnijder 2013; Posey-Maddox, Kimelberg, and Cucchiara 2016). Especially primary schools have been described as 'communities for building social capital' (Karsten 2011), and playing a decisive role in shaping children's but also parents' social networks. Social capital is understood as social networks and the embedded mobilisable forms of capital (see Bourdieu 1980) in these 
networks. These networks may serve as a foundation of local social capital (see Rivière 2014), which in this study refers to the locally based networks, such as a pattern where the adults in the neighbourhood keep their eye on all children in the area, as they know them. From such a perspective, parental trust towards other adults monitoring the children in local public space largely draws on expectations for a reciprocal watchfulness in the neighbourhood (see Sampson, Morenoff, and Earls 1999).

Schooling outside the neighbourhood thus often means a weaker membership in the local networks (Weller and Bruegel 2009). Some families intentionally might avoid the local school based mainly on this idea: they actually are not willing to be socialised in their own neighbourhood. However, this aspect of establishing social networks through school is also one component, which in research might end up embedded or even hidden in the description of families' 'avoidance practices' to 'better' schools outside the neighbourhood, even if the local social capital in the choosing process might be strongly supporting the choice of a local school.

\section{Aim of the study, data and methods}

The aim of this study is to investigate the different ways in which the families perceive the role of access to local social networks in school-choice processes, and to analyse why some families in the three case-cities prefer choosing a school in their socially mixed residential areas. The analysis of social networks is connected to the analysis of surrounding space and spent time in the urban surroundings around the school. The analytical focus has been on analysing the discourses around local social capital presumably mediated through participation in local schooling.

This study is an ex-post comparison of data collected for two different research projects (Kosunen 2016; Rivière 2014), which both deal with families with children and schooling in urban areas in Europe. The goal of this study is not to provide a full comparison across these three contexts, but present how certain social networks in urban areas influence the families' school choices in a fairly similar manner regardless of the local governance of education in each city. A common theoretical and methodological framework for analysing the interviews was created for the purposes of the study, despite the data gathering being conducted 
separately. The interviews conducted in Espoo were gathered as part of a larger project (Parents and School Choice-research project) dealing with lower secondary school choices in Finnish cities. The interviews conducted in Paris and Milan were part of a study focused on parental supervision of children's activities in urban public space (Rivière 2014). The interviews were conducted in Finnish, Italian and French and were translated into English by the authors.

The data consist of semi-structured thematic interviews conducted with parents $(n=170)$, the content dealing with education, mobility practices, parenthood and children's schooling. Half of the interviews ( $n=81$ ) were conducted in Espoo (Finland) in 2011 with 82 parents of at least one child aged 12-13, with a special focus on school choice on the lower secondary level. The rest $(n=78)$ were conducted in Paris (France, $n=35$ ) and Milan (Italy, $n=43$ ) between 2009 and 2012 with 88 parents of at least one children aged 8-14, focusing especially on parental supervision of children activities in urban space. School choices either to primary or lower secondary schools (or both) in urban areas were discussed in all the interviews, as the families in all cities had children attending at least one of these two stages of education.

Social class is considered an important factor constituting the educational practices of families (e.g. Lareau 2003; Power et al. 2003; van Zanten 2009) and is measured here as a combination of the parents' educational level and their position in the labour market. Middle-class was defined by measuring socio-economic differences between social classes based on the possessed forms of capital (Bourdieu 1984): the often-ambiguous middle-class was positioned between the more easily measurable working class and upper class. In this categorisation, people were divided into social groups based on their education and occupational status, and the account for variation across context was dealt with, so that the definitions of each social class are in accordance with their context (meaning that, for example, the absolute income levels of the middle-class in Finland and Italy would not be comparable as such, as the living expenses and average wage levels differ). Middleclass parents' occupations are in all contexts, for example, teachers and engineers, but those are not homogenous groups even within a single national context. Also, the differences in the living standards and, for example, general levels of education in each country differentiate the different classes and make their positions relational. Therefore, the comparison across classes in different contexts is obviously 
challenging, but solved in this study so that the definitions of social class are attached to each context and in the comparative part, it is acknowledged that the social positions discussed remain relational.

Most of the parents in Espoo had a high social status in terms of level of education (usually higher education) and occupational class in relation to the city's and especially the national average: only 6 of these 82 parents were considered working class, the rest middle class (61) and upper class (15). The relative proportions of parents from lower social backgrounds were higher in Paris (7 working-class parents out of 37) and Milan (12 out of 51), despite the fact that middle-class parents constituted the majority in all of our material (36 in Milan, 26 in Paris; 119 parents out of 170 altogether, about $70 \%)$.

The parents were recruited via schools and local educational authorities (Espoo), local associations and snowball sampling (Milan and Paris), and directly in public spaces (Milan and Paris). Based on voluntary participation, the interviews generally lasted between one and two hours. They were conducted in Finnish, French or Italian, and later on subjected to qualitative content analysis. Such analysis was conducted in multiple phases where all discourses concerning the school choice, different forms of capital invested in it, lifestyle practices and the surrounding urban environment were analysed into codes and later merged into larger thematic categories. These codes and categories were crosschecked by the authors. In the next stage, the similar thematic categories, especially concerning the school journeys and social networks of the families, were formulated and compared across local contexts.

When closely investigating the strategies of these families conducting the choice, it seems that a majority of them in all three contexts chose the local public school (44 families in Espoo, 30 in Milan and 26 in Paris). In the data from Espoo, the proportion of parents choosing something else (i.e. always a public school which is not the physically closest one to home) is still high (46\%) in comparison with parents generally conducting a selective choice $(24 \%$ of the whole age-cohort in 2011; Kosunen et al. 2016). This implies the social bias in the interview material of this study with many middle-class families. 


\section{The three urban and educational contexts of the study}

The fieldwork and data gathering were carried out in three delimited local contexts, which all provide a possibility for parental choice, but with different educational policies. The sociohistorical construction of education systems as a part of the welfare state follows different patterns in the three countries, which also affects the ways education and schooling are structurally and socially constructed as part of the society, the life-course and urban space. The provision of schools within the education (quasi-)market and the local school allocation policies thus vary across contexts.

The Finnish case city in this study, Espoo, is the second biggest city of the country (with about 257,000 inhabitants) and is situated in the western part of the metropolitan area of Helsinki, the country's capital. The city comprises different areas varying from the highly urban to the technically rural in the northern parts (which were excluded from this study). We interviewed parents from all except one (rural) catchment area of the city so that every school of the city was the closest one at least to one family: all catchment areas are somewhat socially mixed and no completely gentrified catchment areas existed. The catchment areas were geographically large enough to include several smaller residential areas. However, the average socio-economic level of the city is high even in the Finnish national context, yet the levels of urban segregation remain as high as in the rest of the metropolitan area. In Finland, there is a relatively homogeneous provision of public schools (more than 97\%). School choices are, however, conducted between the different 'soft streams' within the public schools in Finnish cities, meaning additional choices to curriculum (e.g. in maths or arts) in selective classes. In the selective classes, pupils are selected via aptitude-based exams and grouped (separate from those admitted to the general local school classes) based on this choice.

The area investigated in Milan (Monza-Padova) is located in the northeastern part of the city. Of its 76,427 inhabitants in 2008, 23.7\% were non-Italian (a share 10 times higher than 20 years before), which reflects the long history of internal and later on international migration towards this first farming and then small-industry area. As it has good connections (public transport, roads) to the centre of Milan, its population is progressively changing in relation to the de-industrialisation process. In Milan, the combination of a relatively non-hierarchical school market and a more locally and family-oriented organisation of children's daily care 
(Ghezzi 2012) tends to keep children in local schools. The choices take place mainly across private and public schools within the neighbourhood, but also between different selective tracks within the public schools.

The third area of this study $(125,393$ inhabitants in 2008) is located in the 19th district of Paris, also in the northeast of the city. It has several features in common with Monza-Padova and Espoo, in particular its initially rural and then industrial history. The 19th district is a socially and ethnically mixed area (15.7\% of foreigners in 2008$)$ with a relatively low-quality provision of both public and private secondary education, compared with more central districts of the French capital. In Paris, families' school choices have a strong spatial dimension, as the schools are appointed based on school districts and the provision of private schools but also highquality public schools, are unequally distributed within the urban space (Oberti 2007). In secondary schools, families may apply also for other than the local public school (e.g. selective classes in special language tracks) or enrol to private schools.

All three national contexts provide publicly funded tuition-free comprehensive education in local schools, but also introduce a space for school choice within the public or between the public and private schools (mainly Paris and Milan). The main differences across the local contexts are the differing local school-allocation practices and the provision of private comprehensive schooling in Paris and Milan. The general similarity is that the school choices require parental action, constituted from various bureaucratic processes, and the choices to more prestigious classes are mainly conducted by the higher social classes (Kosunen 2016; Rivière 2014). However, we acknowledge the problematic nature of comparing three different urban contexts with different educational histories and practices. Nevertheless, the general procedure of choosing schools in all of these three cities shares certain institutional and practical similarities, as presented above.

\section{Parental concerns, the 'immature child' and children's social networks in public space}

In these three cities, parental concerns related to children's safety in the city, especially during autonomous mobility, was the most often linked to the discussion around the journey to school and whether the journey to school would be made alone, with friends or whether the child should be accompanied by an adult. Journey to school then became a matter of interest 
also in terms of choosing the school itself: would the journey be short and safe enough, and in case the way was longer, what kind of urban skills and time resources would be required from the child and the whole family? The length and the safety of the journey to school were a matter of interest and a general topic of discussion for parents across all three contexts.

The child was often perceived as not competent or mature enough to travel to further schools alone. This immaturity emerged as reasoning in all three contexts, and parents often insisted that they wanted their children to feel confident, and themselves not to worry. Moreover, they perceived the fact of spending of a lot of time without adult supervision as encouraging children to engage in undesirable activities in the city. This concern about children's incapacity to face urban life was consistent with the tendency to consider children as 'incompetent social creatures' in public places (Cahill 1990), which is also evident in Maria's reflection of her son:

Interviewer: Some parents from Espoo apply to Helsinki for a study position in a lowersecondary school. The numbers aren't big, but...

I think it's a question of status, then. My son would not be ready for that. I don't think he would be ready to travel. (...) I don't think the time is right for that yet. I'm not saying that some other child could not do that. My child is just such a hodgepodge that I would never make him undertake such a long journey by himself.

(Maria, engineer, 12-year-old son, Espoo)

Space was discussed in terms of expected physical and social threats, which were related to the distance from home. The ways in which the surrounding urban space was discussed often lead to the practical and financial conclusion of many families preferring the local school, as in addition to less time spent on the way, no additional financial costs occurred. These parents were also familiar with their own neighbourhood's, more so than with other areas in the city, even if the school with an elitist reputation further away would have comprised more prestige. From the point of view of social inequalities in educational choice, the choice of other than the local school was ruled out from some of the working-class families related to the lack of sufficient economic capital, which would have been needed for the public transport to the further school. Therefore, the way in which the middle-class families could actually think of their options near and further from home and then make an intentional choice of the neighbourhood school was a privilege of a kind. 
Apart from the competence of the child to make the journey as such, the parents worried about

outer physical threats along the way to school regardless of its length. Parents were afraid of traffic accidents, particularly near heavily trafficked streets, when there were wide streets to cross, and when the pavements were narrow. The presence or absence of traffic lights was also discussed, as was the number of other children going to school without adults. Reflecting on the social norm of letting (or not letting) the child manage alone in the traffic was important.

To me as a parent the problem is the heavy traffic. We used to live in [high SES area], and back then the [street] was the heaviest residential street regarding traffic in the whole country. Then we had so many it-nearly-happened situations that I was sitting at work dreading it when the phone rang, when I knew she was coming home from there by herself. So the school itself is a safe environment, but the second you get out of there, then you start thinking about what might happen.

(Joel, teacher, 20-, 12- and 10-year-old daughters, Espoo)

In the case of Espoo, the fear of traffic accidents was particularly evident with parents of all schoolchildren, as children are encouraged to go to school autonomously from very early on. In Milan and Paris, parents were more frequently accompanying the children to school until later years, and therefore, this discussion had little less focus than in the case of Finland. However, adult strangers constituted a major concern in all contexts: the stranger-danger was always linked to the perceived safety of the way to the school. This was the case for both boys and girls, even if specific gendered concerns, which are out of the scope of this article, arise after puberty (see Valentine 1997b). Here again, the urban morphology played an important role in all three cities: the tunnels, deserted spaces and dark places were not appreciated.

There is this secondary school located on the other side of the Péripherique [the highway surrounding Paris], which is very unpleasant for parents because the children have to pass under the motorway through a kind of dark tunnel. There are no buses going there, nothing is organised for children to go there safely, so it is quite difficult for parents to let their children go alone to that school. Well-off parents in particular prefer sending their children to a private school or to another public lower-secondary school.

(Marie-Jo, free-lance interpreter and translator, 13-year-old daughter, Paris) 
Marie-Jo makes it clear in this quotation that parents might send their children to another school than the local one not because of the anticipated better quality of schooling, but also because the school journey is safer, even if longer. Parents in Espoo, where children go to and from school in darkness for almost half of the school year (in wintertime), would rather have their children in schools that are easily reachable, but also positioned somewhere else than in vaguely built-up city areas.

The environment is a factor as well. A safe one, kind of like this [local lower-secondary school] for example, it's in the middle of the woods. To me it brings to mind all sorts of stalkers and weirdoes. I would not want to see my child walking along those small paths to school (laughs). [...] I think it's disgusting that you have to tell your first graders, 'don't start talking to any strangers, neither men nor women, and always walk together' [with friends].

(Amanda, project worker, 15-year-old son and 12-year-old daughter, Espoo)

Therefore, the parental concerns related to dangers in the neighbourhood were solved slightly differently across contexts: traffic was a shared concern, which was often solved by accompanying the children to school, especially so in Paris and Milan (where the traffic is also heavier). The stranger- danger (especially in Espoo) was rather solved by children walking to school in groups of friends. Children in Espoo take responsibility for their school journeys from very early on, which shaped the parental discourse around a physically and socially 'safe' school journey, as the children would rather not be accompanied to school. Accompanying children to school was more widely discussed in the cases of Paris and Milan. However, all of these concerns produced by children's everyday geographies of city life in relation with the school journey tended to lose emphasis in the discourse as the children grew older

\section{Families' access to networks and resources derived through the choice of the local school}

The engagement in the local school was presented as promoting families' well-being and providing help in the organisation of everyday family life. These aspects were partly related to the previously presented parental concerns, as the local social network was often discussed as a form of a safety net for the child (and therefore for the whole family) in order to prevent or possibly handle any of the concerns such as the manifestations of the stranger-danger. 
A significant number of parents interviewed thus considered access to the local networks as useful and desirable for the present and also for the future of the family even if the areas were socially mixed into a large extent. Two dimensions could be distinguished: a wish to secure the social integration of children in the neighbourhood (with other children and adults), and an interest in accessing the local networks of adults, that is, making friends and providing and receiving help at the local level. Especially the latter part of the findings can be considered as a novelty of this study, as the importance of the social networks of the parents is hardly mentioned as a reasoning behind schooling practices. This was evident especially among families who had moved to the area from another city and/or did not have their grandparents in the area to support the everyday life after school, which was often the case in Espoo and Paris. The role of the school got then emphasised as a mediating social forum. The interviewees whose children did not attend the local school highlighted the fact that the child's friends lived in other neighbourhoods, which they often considered unfortunate.

As her secondary school is not located in the neighbourhood, she has friends living... Not everywhere in Paris but further from here, so that to visit them she has to take the subway. She has to leave the neighbourhood. Friendship relations take her away from here.

(Maud, certified public accountant, 13- and 10-year-old daughters, Paris)

Parents describe how the school as a mediator is a key factor influencing the child's social networks, and might cause social exclusion in the neighbourhood. Also, maintaining the relations, that is, meeting with friends after school, for example, becomes way more difficult when the friends live in other neighbourhoods. The acquisition of local friends gives a value to going to the neighbourhood school, which operates as a powerful integrating vehicle and mediator of local networks. Local friends and acquaintances were also considered as potentially helpful in regard to the child participating in early autonomous activities in the neighbourhood and in organising the daily life of the family.

What I think is that if you go to a school outside your neighbourhood, and all the more if the school is far away, it is much more difficult to make friends and develop networks of friends. You cannot play with your mates after school for example. [...] I don't want my daughter to live a life in which she feels isolated. I really don't. I think it's important to fully live the neighbourhood experience.

(Céline, project officer, 11-year-old daughter, Paris) 
We decided to take him from [the former school] to the local school, because it was easier to organise our daily lives, but also because we like the idea that he'll grow up in his own neighbourhood. This makes it easier for him to make friends, see them, and maybe later on to be more autonomous in the neighbourhood by having acquaintances here. Because being at school far from home basically means not living but only sleeping here.

(Lisa, civil servant, 8-year-old son, Milan)

As Lisa states, parents considered important for the children to live in the area also in social terms. The ones who did not want their children to be affiliated with the local children also often would have wanted to move out of the neighbourhood: this could also be considered as an indication of striving for the full social experience of the neighbourhood, which in their case would be in some other neighbourhood.

The reasonings behind why to choose a certain school were practical and involved aspects of safety and control in the local neighbourhood through having access to local social networks. Viviane with a bit older children explicitly acknowledged that one reason for her choosing the local school was to make sure that the youngsters who 'roam around' in the area identified her daughters as living there and being 'a local'. Such intentional actions to be acquainted with the local teenagers and recognised as a part of the local social sphere aim to reinforce the children's safety in the neighbourhood. Therefore, the question of children's social ties was not only about the possibilities of positive interaction with other locals, but sometimes also prevention of possibly negative confrontations.

There are groups of youngsters hanging around in the area, and we think that our daughters will have fewer problems if they are identified as living here than if they are not. And the best way to get identified by these youngsters is to go to the same school as them. That was a rather relevant point in our decision. (...) If they go outside when it's dark and meet these youngsters, they can greet each other if they know who they are. This does not mean that nothing bad will happen, but the only fact that they know their names can change a lot of things.

(Viviane, storyteller, 15-, 13- and 10-year-old daughters, Paris)

The gains in terms of local social capital extended also beyond the children's social ties, additionally facilitating the social relations among their parents. There was an underlying idea of shared upbringing in the areas, where also the parents had mutual social networks. 
The children in the school live near you, and they can expand their networks, and you knowthe families and you sort of know the neighbourhood better, and also the child does. Then there's the thing that I hope the other parents, in turn, are also always aware of whose children they are and where they are going, and thereby the network of parents works as a safety net. (Lena, teacher, 18-, 12-, 11- and 5-year-old sons and a 17-year-old daughter, Espoo)

Schoolmates are very precious, this is a great added-value of the local public school in which all the schoolmates live nearby. Because when you go to a private school there are pupils coming from further away. Whereas in the local public school you'll find your neighbours. This is very interesting because you often meet the schoolmates in the streets. So that if there is a problem, the child can ask his friend for help. This is really reassuring for parents when they [the children] get more autonomous. Because the schoolmates are close by, and so are their parents.

(Aliénor, housewife, 12- and 3-year-old daughters, 12- and 8-year-old sons, Paris) Choosing a local school was also an efficient mechanismthrough which parents themselves could join the local social networks, and make neighbourhood allies and friends, which often remains in the background of discussions around children's schooling and educational choice of younger pupils. The parents tended to consider other families' houses as safe havens for their own children, if they had problems getting to school on time, or needed to find pre- or post-school childcare, for example. The school as a gateway to local 'solidarity networks' may thus motivate the choice of the local school:

I've always been aware of the importance of sending our girls to the local school. (...) I always wanted them to make connections in the neighbourhood. If I had made the choice of a more prestigious school in the city centre, they would not have been rooted here. (...) As we do not have grandparents living close to us it is definitely a great help that the girls go to the same school as the children living here. If we can't pick up our daughter we just call another mother, who will pick her up and take her home. We continuously supply and benefit from mutual help, which makes it easier for many families to cope with the daily life.

(Roberto, teacher at upper-secondary school, 14- and 9-year-old daughters, Milan)

The choice of a local school also gave parents the opportunity to develop their own social lives, 
especially if they were not originally from the area. Schools functioned as local mediators of parental socialisation into the local life: parents forge social connections and sometimes make friends through school. The parents' personal relationships developed through the local school, which also created a feeling of belonging. Access to dense networks bringing information, mutual help and friendship ties partly explained why a child's leaving the local school can be considered socially costly for the parents themselves. In fact, school choice did not only deal with choosing once between different potential networks (i.e. local networks vs. non-local networks), but also with remaining involved in the accessed networks through the local school.

The school really changes your relationship with the neighbourhood, it brings in relations with the other people living here...(...)We've had a lot of great moments, thanks to school (...) I have the feeling that it has been the same for my friends all around Paris. Primary school is a place for social encounters. I mean, you can't be aware of the school's role in parents' lives until you become a parent.

(Marianne, museum guide and lecturer, two 14- year-old daughters, Paris)

She still has two years to go at primary school. She has good friends here but she wants to go to another school. My partner and I are very well established here via the school, and this is a big problem for us. I like this school, but she [the daughter] doesn't. The thing is that she has no serious problems regarding her learning outcomes, so we are not worrying about her education here. I hope I can manage to keep her here until lower-secondary school.

(Gabrielle, journalist, 9-year-old daughter, Paris)

Parental choices have to be considered simultaneously as based on anticipations (a desire to establish networks, as illustrated by the case of Roberto) and embedded in previous choices (a desire to maintain networks, as illustrated by the case of Gabrielle). In all cases, local schooling appears to be a very efficient way of benefiting from different kinds of resources associated with higher amounts of local social capital.

\section{Conclusion}

The local school clearly works as a social mediator of both children's and adults' relationships in the area, especially in the primary school phase. The reasoning behind choosing the school was generally discussed as locally traditional or demonstratively ideological, but further analysis revealed that the choice was simultaneously strongly related to everyday family life 
in the neighbourhood, as could be expected (see Posey-Maddox, Kimelberg, and Cucchiara 2016). This notion appeared across national and local educational contexts among families. It suggests that there is something universal in the way school choices are partly shaped by concerns related to children's safety and daily mobility practices.

These findings deepen the notion of choosing the school as a political or ideological question (Raveaud and van Zanten 2007) but primarily stress the practical and urban aspects of the choice. Politically and ideologically, many parents brought up the importance of choosing a local school, which as a rationale follows the findings of previous studies. However, when talking about safety in the urban area around the school, mediated by the social relationships gained through local school participation, the political and ideological reasonings get a more practical touch. The discussion of responsible citizenship (Posey-Maddox, Kimelberg, and Cucchiara 2016; van Zanten 2009) and good parenthood as looking for the best match of a school (Oría et al. 2007) for their child becomes more complex: the families might make a school choice of the local school due to safety, feasibility and access to local social networks. The rationale of the safety does not primarily involve the safety inside the school, but rather outside the school building within the surrounding public space. Another promoted aspect in addition to safety was the discussed extended feasibility of the everyday life due to mutual help of families in the neighbourhood. The everyday geographies of city life were discussed by parents across contexts regardless of their final decision of which school to choose.

The aim of accessing local social capital is influencing families' school-choice processes. Choosing the local school may thus be a strategy oriented towards the accumulation of local social capital, in order to ensure the safety of the children in the neighbourhood during their free time through shared parental control. The social relations that are mediated via school with both local children and their parents also may contribute to higher well-being, as being involved in these school-mediated local social networks would, according to the parents, increase the likelihood of receiving mutual help in different situations. These social ties sharpen the parents' perceptions of the local social environment, which, in turn, seem to make them worry less about their children's safety in the neighbourhood. Their trust towards other adults monitoring of the children in the local public space draws on expectations from a reciprocal watchfulness in the neighbourhood (see Sampson, Morenoff, and Earls 1999). This 
again may promote the choice of a local school, as it brings along an extended physical and affective micro-space for the families to interact in (see Vincent, Neal, and Iqbal 2016) in the neighbourhood.

However, independently of the social background of the parents, their interest for keeping the

school journey short and safe or accessing the local networks of children and parents was significantly lower at the secondary school level than at the primary level, as the older children were more autonomous in urban space (see also Lehman-Frisch, Authier, and Dufaux 2012; Weller and Bruegel 2009). The everyday geographies in school choice thus appear more essential in parents', decision-making at the primary school level in the three cities of this study, as they concern aspects of safety and control. The only peculiarity was the Finnish way of basically not considering accompanying the child to the school, but choosing a school into which the child could go autonomously already in the first grade.

Finally, the adult-adult relationships mediated by the children's schooling in urban areas were brought up in the analysis: a part of the choice agenda, which is usually not discussed, as the choice is often treated as the child's choice due to his/her reasons. Therefore, it seems that in these three contexts knowing the children and adults of the area through participation in the local schooling is considered important not only because of the children, but also because of the parents. Table 1 draws together our central findings concerning the expected consequences of social networks around the local school. All of them had an influence on the ways in which the families reasoned their choices of schools in all three cities.

Table 1. The variation in the forms of local social networks and the expected consequences related to maintaining or developing those networks in the neighbourhood.

\begin{tabular}{c|l}
\hline $\begin{array}{c}\text { Social networks in the neighbourhood } \\
\text { mediated by the local school }\end{array}$ & $\begin{array}{l}\text { Expected consequences } \\
\text { Children know each other in the area } \\
\text { on their free time, being acknowledged as a local kid } \\
\text { provides safety in public space }\end{array}$ \\
\hline Children know other children and their parents & $\begin{array}{l}\text { Shared parental control: 'street watchers', children's } \\
\text { and parents' feeling of safety and belonging to the } \\
\text { local community }\end{array}$ \\
\hline
\end{tabular}


The reasonings behind the choice were a combination of different affective, practical and ideological reasons related to the city as living environment. What is clear is that the social networks embedded in the schooling were crucial parts in the reasoning of the choice of a local school for all families across social classes and national contexts. Our study highlights how parents can also benefit in different ways from the choice of the local school and secure a variety of resources such as mutual help, information, collective supervision of children's activities in public space and even friendships. Along the school-choice process, all families have to deal with these everyday geographies of city life, which also seem to have some sort of universal explanatory power.

\section{References}

Ball, Stephen J., Richard Bowe, and Sharon Gewirtz. 1995. "Circuits of schooling: a sociological exploration of parental choice of school in social-class contexts." The Sociological Review 43: 52-78.

Ball, Stephen J., and Carol Vincent. 2007. "Education, Class Fractions and the Local Rules of Spatial Relations." Urban Studies 44 (7): 1175-1189.

Ball, Stephen J., and Carol Vincent. 1998. "'I Heard It on the Grapevine'. 'Hot' Knowledge and School Choice." British Journal of Sociology of Education 19 (3), 377-400.

Bell, Courtney A. "All choices created equal? The role of choice sets in the selection of schools." Peabody Journal of Education 84 (2): 191-208.

Berends, Mark. 2014. "The Evolving Landscape of School Choice in the United States." In H. R. Milner IV \& K. Lomotey (eds.) Handbook of Urban Education. New York \& London: Routledge, 451-473.

Bourdieu, Pierre. 1980. "Le capital social. Notes provisoires." Actes de la recherche en sciences sociales 31: 2-3.

Bourdieu, Pierre. 1984. Distinction: A social critique of the judgement of taste. Cambridge: Harvard University Press. 
Bunar, Nihad, and Anna Ambrose. 2016. "Schools, choice and reputation: Local school markets and the distribution of symbolic capital in segregated cities." Research in Comparative and International Education: 1745499916631064.

Butler, Tim, and Garry Robson. 2003. London calling. The Middle Classes and the Re-Making of Inner London. Oxford: Berg.

Butler, Tim, and Agnès van Zanten. 2007. "School choice: a European perspective." Journal of Education Policy 22 (1): 1-5.

Cahill, Spencer E. 1990. "Childhood and public life: reaffirming biographical divisions." Social Problems 37 (3): 390-402.

Ghezzi, Simone. 2012. "Parenthood and the structuring of time among urban households in northern Italy." Ethnologie française 42: 37-74.

Gustafson, Katarina. 2011. "No-go- area, no-go- school: community discourses, local school market and children's identity work." Children's Geographies 9(2): 185-203.

Holloway, Sarah, Phil Hubbard, Heike Jöns, and Helena Pimlott-Wilson. 2010. "Geographies of education and the significance of children, youth and families." Progress in Human Geography, 34(5), 583-600.

Karsten, Lia. 2005. "It all used to be better? Different generations on continuity and change in urban children daily use of space." Children's Geographies 3 (3): 275-290.

Karsten, Lia. 2011. “Children's social capital in the segregated context of Amsterdam: an historical-geographical approach." Urban Studies 48 (8): 1651-1666.

Karsten, Lia, Tineke Lupi, and Marlies de Stiger-Speksnijder. 2013. "The middle classes and the remaking of the suburban family community: evidence from the Netherlands." Journal of Housing and the Built Environment 28 (2): 257-271.

Karsten, Lia. 2015. “Middle-class childhood and parenting culture in high-rise Hong Kong: on scheduled lives, the school trap and a new urban idyll." Children's Geographies 13(5): 556-570.

Kosunen, Sonja. 2016. Families and the social space of school choice in urban Finland. Helsinki: Unigrafia.

Kosunen, Sonja, Venla Bernelius, Piia Seppänen, and Miina Porkka. 2016. "School Choice to Lower Secondary Schools and Mechanisms of Segregation in Urban Finland." Urban Education. DOI: 10.1177/0042085916666933.

Kosunen, Sonja. "Reputation and parental logics of action in local school choice space in Finland." Journal of Education Policy 29 (4): 443-466. 
Lareau, Annette. 2003. Unequal Childhoods: Class, Race, and Family Life. Berkeley, CA: University of California Press.

Lehman-Frisch, Sonia, Jean-Yves Authier, and Frédéric Dufaux. 2012. "'Draw me your neighbourhood': a gentrified Paris neighbourhood through its children's eyes." Children's Geographies 10 (1): 17-34.

Lofland, Lyn. 1973. A World of Strangers. Order and Action in Urban Public Space. New York: Basic Books.

McMillan, Tracy E. 2005. “Urban form and a child's trip to school: the current literature and a framework for future research." Journal of Planning Literature 19: 440-456.

Oberti, Marco. 2007. L'école dans la ville. Paris: Presses de Sciences Po.

Oría, Angela, Alejandra Cardini, Stephen Ball, Eleni Stamou, Madga Kolokitha, Sean Vertigan, and Claudia Flores-Moreno. 2007. "Urban education, the middle classes and their dilemmas of school choice." Journal of Education Policy 22 (1): 91-105.

Pain, Rachel. 2006. "Paranoid parenting? Rematerializing risk and fear for children." Social \& Cultural Geography 7 (2): 221-243.

Posey-Maddox, Linn, Shelley McDonough Kimelberg, and Maia Cucchiara. 2016. "Seeking a "critical mass": middle-class parents' collective engagement in city public schooling." British Journal of Education 37 (7): 905-927.

Power, Sally, Tony Edwards, Geoff Whitty, and Valerie Wigfall. 2003. Education and the middle class. Buckingham: Open University Press.

Raveaud, Maroussia, and Agnès van Zanten. 2007. "Choosing the local school: middle class parents' values and social and ethnic mix in London and Paris." Journal of Education Policy 22 (1): 107-124.

Reay, Diane. 2004. "Exclusivity, exclusion, and social class in urban education markets in the United Kingdom." Urban Education 39 (5): 537-560.

Rivière, Clément. 2014. Ce que tous les parents disent? Approche compréhensive de l'encadrement parental des pratiques urbaines des enfants en contexte de mixité sociale (Paris-Milan), PhD dissertation in Sociology, Sciences Po Paris/Università degli studi di Milano-Bicocca. 
Sampson, Robert J., Jeffrey D. Morenoff, and Felton Earls. 1999 "Beyond social capital: spatial dynamics of collective efficacy for children." American Sociological Review 64 (5): 633-660.

Seppänen, Piia, Alejandro Carrasco, Mira Kalalahti, Risto Rinne, and Hannu Simola (eds). 2015. Contrasting Dynamics in Education Politics of Extremes: School Choice in Chile and Finland. Rotterdam: Sense Publishers.

Taylor, Chris. 2001. "Hierarchies and 'local' markets: the geography of the 'lived' market place in secondary education provision." Journal of Education Policy 16 (3): 197214.

Valentine, Gill. 1997a. "A safe place to grow up? Parenting, perceptions of rural safety and the rural idyll." Journal of Rural Studies 13 (2): 137-148.

Valentine, Gill. 1997b. "'My son is a bit dizzy'. 'My wife is a bit soft': gender, children, and cultures of parenting" Gender, place and culture 4 (1): 37-62.

Valentine, Gill, and John McKendrick. 1997. “Children's outdoor play: exploring parental concerns about children's safety and the changing nature of childhood." Geoforum 28 (2): 219-235.

van Zanten, Agnès. 2009. Choisir son école: stratégies familiales et médiations locales. Paris: Presses Universitaires de France.

Vercesi, Monica. 2008. La mobilità autonoma dei bambini tra ricerca e interventi sul territorio. Franco Angeli: Milan.

Vincent, Carol, Sarah Neal, and Humera Iqbal. 2016. "Children's friendships in diverse primary schools: teachers and the processes of policy enactment." Journal of Education Policy 31 (4): 482-494.

Weller, Susie, and Irene Bruegel. 2009. “Children's 'place' in the development of neighbourhood social capital." Urban Studies 46 (3): 629-643.

\section{Acknowledgements}

We would like to thank the anonymous reviewers of Children's Geographies for their insightful comments. We are also grateful to professors Agnès van Zanten, Marco Oberti, and Piia Seppänen for their insightful comments on earlier versions of this article. The responsibility of the content remains with the authors. 


\section{Disclosure statement}

No potential conflict of interest was reported by the authors. 